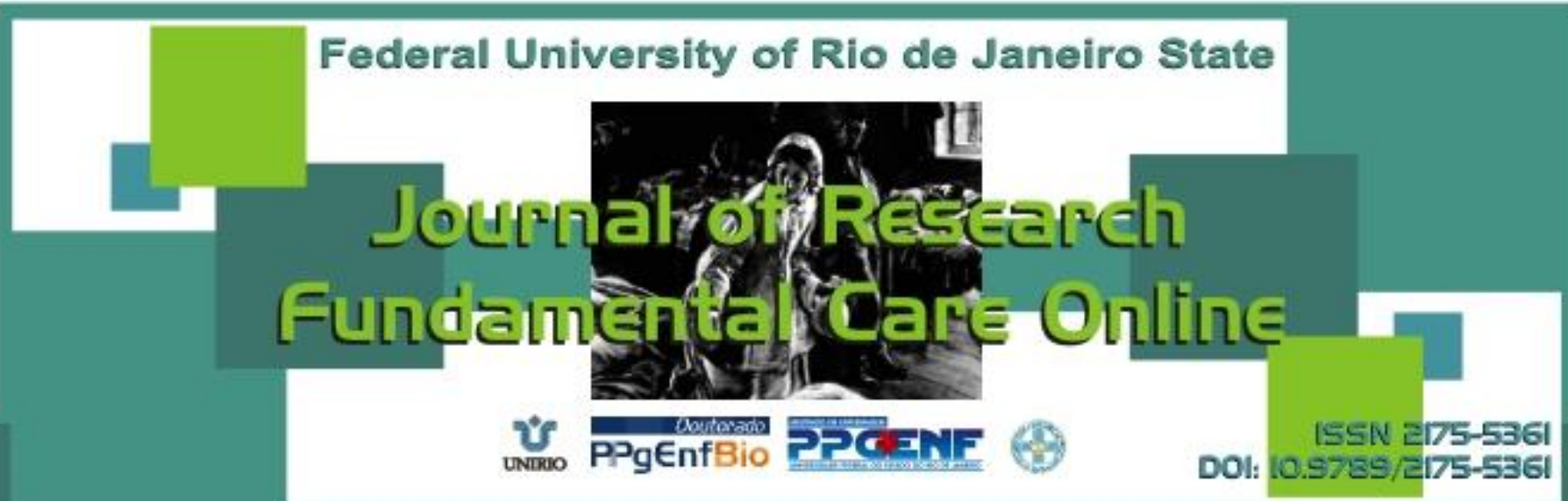

\title{
REVIEW
}

\section{Guidelines for intravenous therapy in elderly: a bibliographic research}

Diretrizes para terapia intravenosa no idoso: pesquisa bibliográfica

Directrices para la terapia intravenosa en los idosos: investigación documental

Daniela Fernandes de Lima Oliveira ${ }^{1}$, Rosemeiry Capriata de Souza Azevedo ${ }^{2}$, Maria Aparecida Munhoz Gaiva ${ }^{3}$

ABSTRACT

Objective: To know the specific recommendations of intravenous therapy in the elderly. Method: Bibliographical research, the data sources were Policies and Procedures for Infusion Nursing of the Older Adult, Infusion Nursing Standards of Practice, Policies and Procedures for Infusion Nursing, Practice guidelines for intravenous therapy and Guidelines for the Prevention of Intravascular Catheter Related Infections and analyzed based on content analysis. Results: the professional must know the anatomical and physiological changes of aging, including patients and families in the education process; the puncture site should be greater quantity of subcutaneous tissue and bone support in selecting the catheter considering the smallest gauge possible for therapy prescribed. It is important to obtain a complete history of medications used, including the non-prescribed, phytotherapeutic or homemade preparations. Conclusion: The recommendations show how the elderly are different from young adult; this implies modifications and adaptations in the planning and development of nursing care. Descriptors: Elderly, Health planning guidelines, Education of nursing, Central venous catheterization, Peripheral venous Catheterizations.

RESUMO

Objetivo: Conhecer as recomendações específicas da terapia intravenosa no idoso. Método: Pesquisa bibliográfica, as fontes de dados foram Policies and Procedures for Infusion Nursing of the Older Adult, Infusion Nursing Standards of Practice, Policies and Procedures for Infusion Nursing, Diretrizes práticas para terapia intravenosa e Guidelines for the Prevention of Intravascular Catheter Related Infections e analisados com base na análise de conteúdo. Resultados: o profissional deve conhecer as mudanças anatômicas e fisiológicas do envelhecimento, incluir pacientes e familiares no processo de educação; o sítio de punção deve ter maior quantidade de tecido subcutâneo e suporte ósseo, na seleção do cateter considerar o menor gauge possível para a terapia prescrita. É importante obter o histórico completo de medicamentos usados, incluindo os sem receita médica, fitoterápicos ou preparações caseiras. Conclusão: as recomendações mostram o quanto o idoso é diferente do adulto jovem, isso implica em modificações e adaptações no planejamento e evolução do cuidado de enfermagem. Descritores: Idoso, Diretrizes de planejamento em saúde, Educação em enfermagem, Cateterismo venoso central, Cateterismo venoso periférico.

RESUMEN

Objetivo: Conocer las recomendaciones específicas de la terapia intravenosa en los ancianos. Método: Búsqueda bibliográfica, las fuentes de datos fueron Policies and Procedures for Infusion Nursing of the Older Adult, Infusion Nursing Standards of Practice, Policies and Procedures for Infusion Nursing, Directrices prácticas para la terapia intravenosa y Guidelines for the Prevention of Intravascular Catheter Related Infections y analizados con base en el análisis de contenido. Resultados: los profesionales deben conocer los cambios anatómicos y fisiológicos del envejecimiento, incluir los pacientes y las familias en el proceso educativo, el lugar de la punción debe tener mayor cantidad de tejido subcutáneo y soporte óseo en la selección del catéter considerar el menor calibre posible para la terapia prescrita. Es importante obtener un historial completo de los medicamentos utilizados, incluidas las preparaciones de venta libre, remedios herbales o preparaciones caseras. Conclusión: Las recomendaciones muestran cómo los ancianos son diferentes de los adultos jóvenes, lo que implica modificaciones y adaptaciones en la planificación y desarrollo de la atención de enfermería. Descriptores: Ancianos, Guías de planificación en salud, Educación en enfermería, Cateterismo venoso central, Cateterismo venoso periférico.

${ }^{1}$ Master of Nursing Program of Postgraduate Nursing, Federal University of Mato Grosso - UFMT, Cuiabá (MT), Brazil, Email: dflimaoliveira@gmail.com ${ }^{2}$ PhD, Professor, Graduate Program in Nursing and Member of Project Argus Research Group, School of Nursing, Federal University of Mato Grosso, Cuiabá (MT), Brazil, Email: capriata@terra.com.br . Corresponding Author: Rua C, $n^{\circ} 33$, apto 501. Cond. Matisse Residences, Miguel Sutil, Cuiabá, MT, Brazil, 78048-298. Email: capriata@terra.com.br, ${ }^{3}$ C, $\mathrm{n}^{\circ}$ 33, apto 501. Cond. Matisse Residences, Miguel Sutil, Cuiaba, MT, Brazil, 78048-298. Email: capriata@terra.com.br ,
PhD in Nursing. Professor of the Graduate Program in Nursing, Group Leader Research Project Argos School of Nursing, Federal University of Mato Grosso, Cuiabá (MT), Brazil and CNPq Researcher, Email: mamgaiva@yahoo.com.br. 


\section{INTRODUCTION}

ith the evolution in acute and chronic treatments, technologies related to intravenous therapy became more complex, diverse and content of the process of professional nursing education. It is an activity conducted daily with progressively increasing demands, responsibilities and scientific ${ }^{1}$.

Seeking the implementation of safe practices in infusional, national and international bodies produced papers with recommendations that assist health professionals in control and reducing complications, safety and patient satisfaction, the cost management and the production of knowledge $\mathrm{e}^{2-6}$.

The issue of patient safety has received notoriety in the last decade, when there was an intensification of surveillance and conformity to quality standards, advances in knowledge, notification and management of complications by health institutions and regulatory bodies ${ }^{7}$.

However, problems related to intravenous therapy are frequent in health institutions and affect patients of different age groups, and the potential risk for the occurrence of complications falls on newborns and the elderly. The elderly are subject to occurrence of iatrogenic events because they are often treated like any other adult patient without considering the uniqueness of the process of senescence and senility, or often, lack of knowledge, planning, and specialized protocols for this population ${ }^{2,4,5,8}$.

No Brazilian guidelines for intravenous therapy with specific recommendations for the elderly. Brazil The Infusion Nurses Society (INS) ${ }^{3}$ brings recommendations just for adults, children and neonates.

Already Guidelines drawn up by international bodies can be obtained only in specialized electronic addresses by buying foreign currency, and are only available in the English language, ie, it is necessary that nursing professionals have fluency in that language. Anyway, being recent documents, drafted in 2011, there are few scientific articles that are based on their recommendations.

Potential complications of intravenous therapy due to aging and lack of institutional protocols specific to the elderly, deficiencies in training, scarcity of studies and the absence of national guidelines that support nursing practice in intravenous therapy to the elderly can considerably compromise the safety of that patient and quality of nursing care.

For these reasons, knowing the existing recommendations regarding intravenous therapy for the elderly is crucial, since it allows identifying the potential complications associated with aging, develop specialized protocols, support improvements in vocational training and contribute to national surveys focused on safe practice of nursing. Thus, the aim of this study is to know the specific recommendations of intravenous therapy for the elderly, gifts Guidelines organs specialized in infusional. 


\section{METHOD}

This is a bibliographical research with a qualitative approach. The literature is a mode of study and analysis of the scientific papers and is related to the contribution of different authors on a particular theme, called the state of the art knowledge 9

The sources were five Guidelines prepared by expert bodies in infusional, recognized nationally and internationally.

- Policies and procedures for infusion nursing of the older adult ${ }^{2}$ : Published in 2004 by Infusion Nurses Society (INS), is the only specific guideline for the elderly;

- Infusion nursing Standards of practice ${ }^{3}$ e Policies and procedures for infusion nursing ${ }^{4}$ : Are the INS guidelines with recommendations for different populations and care settings in intravenous therapy, were revised and published in March 2011.

- Practice guidelines for therapy intravenous ${ }^{7}$ : Published by INS Brazil in 2008, is the first national guideline on intravenous therapy in the country;

- Guidelines for the prevention of intravascular catheter-related infections ${ }^{8}$ : Published in the second half of 2011 by the Centers for Disease Control and Prevention $(C D C)$, with recommendations for the prevention and control of infections related to intravenous catheters.

The analysis of the documents was performed after translation to adequately determine the meanings of terms and concepts, as only one document was in the native language. The translation was also an important step in preparing the information to be analyzed and allowed the completion of the encoding process to identify the materials of each element to be analyzed messages.

This moment was critical to approach/identification details of documents, knowledge of technologies and new concepts that guided the literature search of current articles, with credibility and to substantiate the analysis of documents.

The translation and cultural adaptation of the terms were made by one of the study authors and discussed in the research group. To this end, we need full mastery of the English language and profound theoretical and practical processes involving intravenous therapy in adult and elderly.

After this step was sought on the specific recommendations for the elderly, discarding those that referred to adult in general. We used the technique of content analysis that supported the identification, organization, categorization and analysis of communication elements present in documents ${ }^{9}$. This process resulted in three categories: assessment and care planning for the elderly in intravenous therapy; Care puncture site and intravenous devices and management of complications of intravenous therapy. 


\section{RESULTS}

Documents analyzed, prepared by $\mathrm{CDC}^{6}$ brought no specific recommendation for the elderly, but it is understood that this subject was considered in some general recommendations, for example, those related to hand hygiene, which are applied to the care regardless of the population (adult, child, newborn, elderly).

Already produced by $\mathrm{INS}^{2-5}$, approached the elderly with emphasis on different aspects. The document "Policies and procedures for infusion nursing of the older adult" was produced specifically for the elderly population, and provides recommendations regarding: assessment and care planning for the elderly in intravenous therapy, care of the puncture site and intravenous devices and management complications of intravenous therapy. Their recommendations are based on a theoretical old (1992-2003) qualitatively and quantitatively restricted. Additionally, these recommendations do not have descriptions or classifications as to its relevance or scientific weight.

The Document "Infusion Nursing Standards of practice"4 has few recommendations related to assessment and care planning for the elderly in intravenous therapy and care of the puncture site and intravenous devices. Their recommendations were developed by some clinical articles, books and specialized guides based on consensus standard or accepted practice, but that have no scientific basis. Thus, they are not substantiated by randomized controlled studies, meta-analysis or well-designed clinical studies demonstrating scientific fragility and scarcity of well-designed studies.

Already the document "Policies and procedures for infusion nursing" ${ }^{5}$ has a single recommendation for this population regarding the care of the puncture site and intravenous devices. And the National Document "Practice guidelines for intravenous therapy" ${ }^{3}$, brings no quotes related to the elderly throughout your content.

\section{ASSESSMENT AND PLANNING OF THE ELDERLY CARE IN INTRAVENOUS THERAPY}

The elderly may require intravenous therapy due to several factors involving their health condition (acute or chronic), and clinical diagnostics. To be performed safely, it is recommended that the professional knows the anatomical and physiological changes of aging, as these factors may influence the choice of vascular and non-vascular devices, onsite and puncture technique, selection of special equipment infusion, care and development of dose/volume of drugs ${ }^{2}$.

The cognitive, psychological, social, environmental and economic assessment helps in communication, education/guidance, development and preservation of the elderly patient activities of daily living (ADLS). Thus it is recommended that ${ }^{2,4}$ family members, caregivers or legal representatives should participate in the planning and care as if they were members of the healthcare team. 
The care planning for elderly patients includes medical record notes, consent forms, notification of unusual occurrences, patient education and family and plan of care and discharge. The medical record notes is an important tool of communication between members of the health team and to consider the care of the elderly, it is recommended ${ }^{2}$ to document their functionality or physical and cognitive deficits, as well as the consent of the patient that may interfere in decisions regarding therapy. The registry of information about the functionality of the elderly facilitates the selection of equipment and devices suitable for the guarantee of a continuous infusional and effective.

In addition, the elderly present special conditions regarding its safety, the record of these occurrences should include limitations, deficits, facilities and difficulty in performing activities of daily living (ADLS). One can also consider special occurrences, unexpected reactions to medications or unpleasant parenteral injuries resulting from errors during infusions or related equipment infusions, catheter insertion, breach of aseptic technique or equipment defective/malfunction. These records must be adequate monitoring and include the measures taken for its correction, planning for potential losses and health implications for the elderly².

As for patient education, it is important for the elderly learning more about their health condition, stimulates active participation in self-care practices and should also involve their families and caregivers. For best results the method chosen should be appropriate to the emotional state, physical and cognitive abilities of the elderly and caregiver².

Thus, it is necessary to follow some steps, how to determine the prior knowledge of the elderly and caregivers about the information to be transmitted, speak clearly, slowly and in a tone of voice appropriate to avoid technical terminology and remain face to face with the elderly to better understanding. The written materials must be formatted in letter fonts for easy reading, with double spacing and wide margins, using educational materials according to the educational level of the elderly, with illustrations and lackluster roles in order to individualize the teaching according to the needs of each patient ${ }^{2}$.

In addition, it is recommended ${ }^{2}$ that information to be passed in sequence and logic procedures/care will be realized. The educational process should be strengthened, revised and reassessed frequently, but should be divided into short sections, it is important to ask the patient to return knowledge, the opportunity to work together with the professional and retention of higher information content.

As for the plan of care and high, it is important that this be clearly documented so that all staff have access to details about the main points of therapy, specific problems, recommendations, timelines and milestones. The clinical management of elderly patients should be present in the political and institutional norms, guidelines and protocols, procedures and / or professional practice, and apply the standards of the institution ${ }^{2}$.

\section{CARE WITH THE LOCAL OF THE PUNCTURE AND INTRAVENOUS DEVICES}

When selecting the site for insertion of catheters, it is necessary to consider the changes in cutaneous and vascular system of the elderly, the type and duration of treatment, once aging is loss of subcutaneous tissue, dryness, sagging and thinning skin, 
besides hardening and thickening of the vascular structures. Consequently, insertion, positioning and fixing of intravenous catheters can be difficult and risks of injury, phlebitis and infiltration increases. Thus, the nurse should select areas with higher amounts of subcutaneous tissue and bone support, considering the conservation and integrity of the vascular access for future intravenous therapy ${ }^{2}$.

It is also necessary to preserve the independence and $A D L$ of the patient, allowing you to use your hands and does not restrict most of their movements, providing greater comfort and minimize the possibility of catheter displacement or tangling the catheters and accessories. For this it is important to know whether it is left or right handed, using support bracket for locomotion and ask the patient's preference regarding the positioning of the catheter, as he often has a history of hospitalization and knows its operation. Thus, it is not recommended catheter insertion areas on the hands and bending ${ }^{2}$.

Regarding the selection of the catheter Guidelines that bring specific recommendations for the elderly ${ }^{2,4-5}$ recommend that nurses should consider the smallest gauge possible for the prescribed therapy. For the short term, indicates the use of catheters on short needles 22-24 gauges. Greater caliber catheters can be used in blood transfusion and derivatives ( 20 or 22 gauges) or rapid volume infusions ( 18 or 20 gauges).

Additionally, we recommend ${ }^{2-4}$ nurses review the qualifications of the nursing staff, the difficulty and time required for maintenance, loss and replacement of the device. Catheters with wings of steel should be used only for short infusions (1-4 hours, the average insert and Peripherally Inserted Central Catheters (PICC) for patients requiring venous access frequently, continuously or intermittently or having limited access. It is also necessary to assess if the elderly has restrictions on the positioning of catheters in jugular and subclavian.

As the skin preparation for intravenous catheter insertion, it should be considered ${ }^{2}$ alcoholic solutions which can cause irritation, dryness and discomfort, and achieve lower patient compliance procedures. Due to the fragile skin of the elderly, extra care must be taken to rub antiseptic on the skin to not annoy her or injured her. Despite the restrictions mentioned in any of the documents analyzed were observed recommendations against indication to the use of some antiseptic for the elderly ${ }^{2-6}$.

Regarding puncture technique stands out ${ }^{2}$ that the professional may have difficulty penetrating the wall of the vein due to its hardening, thickening, loss of elasticity and support ("vein dancer"). Additionally, there may be delays in vasodilation and blood return puncture (flashback). Thus, attention is needed to advance the catheter to not cause injuries, bruises, infiltration or extravasation. For this, the nurse should ensure the stabilization of vein puncture, being careful not to apply a tourniquet for a long time and tension, which can further complicate the procedure, causing injuries, skin lacerations and changing laboratory test results ${ }^{2}$.

Elderly may become disoriented stirred with tourniquet application, it is recommended for such application that ${ }^{2}$ does not exceed 2 to 3 minutes, if possible it is positioned on the clothing for added comfort, it is removed during the preparation of materials for venipuncture and should be single-use latex-free .

After insertion, it is suggested that the devices ${ }^{2,4}$ are fixed with sutures or adhesives designed specifically for this purpose. These are used to prevent accidental displacement, 
self injury or damage to the veins in populations with cognitive limitations, or having a high risk of accidental dislodgement of the device, such as children and the elderly. Importantly, the use of these materials allows the visualization of the site, and also preserves the integrity of the skin, since due to the skin fragility and susceptibility of the elderly, that can develop signs of allergy adhesive such as itching, redness and lesions case is removed improperly ${ }^{2,4}$.

It is important to avoid dressings often opaque and assess the integrity of the skin in relation to reactions to antiseptics, adhesives, pressure areas and presence of maceration caused by moisture (leaks or body fluid). In addition, the dressings must be applied and removed using aseptic technique. Have your exchange should occur when there is loss of integrity, moisture or at specific intervals: every 48 hours for gauze dressings; every new puncture (short peripheral catheters): from 3 to 7 days (other catheters) ${ }^{2}$.

Another way to protect the venous catheter is through the use of gloves/splints tracks and support for hands and arms. The use of devices that limit physical mobility should be avoided whenever possible, in addition, the nurse must be enabled/able to display it, apply it and remove it. Attempts to prevent removal of the devices and the need to physically restrict the individual involvement is indispensable interdisciplinary team, families and carers in planning and collaboration in care, not forgetting, the progressive and continuous educational reinforcement ${ }^{2,4}$.

Splints for arm support are especially suitable for catheters placed in local bending, but special attention should be given when placed in the hands or wrists of the elderly if it shows evidence of arthritis in the joints or modifications. These regions also have the need for extra cushioning on the plate to prevent discomfort or stiffness. Need to be removed at predetermined intervals for evaluation of peripheral circulation and movement supervised limb, or so the patient's condition permits. The patient should be instructed to move other joints of the extremities (fingers, shoulders) to improve circulation and prevent stiffness. Tapes that are used to attach the base plates for the arms must be covered with gauze strips or be appropriate in preventing skin damage ${ }^{2}$.

From the moment in which the catheter is positioned securely starts the infusion of drugs. For this, accessories are required for equipment such as catheters and IV pole and infusion pumps/flow controllers, extenders, filter, injectors/ports or multiple access devices, needleless connectors/needleless systems and catheters. In the elderly is recommended that the second luer-lok ${ }^{\mathrm{TM}}$, system is because the connection is more accurate and reliable, thus minimizing the possibility of accidental separation or disconnection of a device.

The catheters and stents may pose a problem for visually impaired older adults, bedridden, or cognitive impairment, as these can curl up in bed linen, side rails and other furniture, causing displacement of the devices. A long team may also be a risk to patient safety, creating the possibility of stumbling, falls and injuries ${ }^{2}$.

For patients with water control, it is recommended the use of catheters droplets when infusion rates are less than $60 \mathrm{ml} / \mathrm{h}^{2}$. Strict control of the flow of the infusion in elderly patients is very important, as they can be sensitive to rapid fluctuations in volumes in circulation. The use of flow control equipment is essential for this population may be mechanical, electronic, or infusion pumps ${ }^{2}$. 
As for the holders for controlling the infusion serum and enable independent and ADL performance without stopping the infusion, but should not be mistaken as "walkers" or used to assist in locomotion. This equipment must have broad-based and small center of gravity to prevent tipping, height adjustment and palmrest, its maintenance should be done regularly to ensure proper movement of the wheels, avoiding the risk of crash. If a support or walker for ambulation is necessary, it is better that it be an integral part of this material. Support fixed infusion is ideal for elderly bedridden or who are receiving intermittent infusions ${ }^{2}$.

\section{MANAGEMENT OF COMPLICATIONS OF INTRAVENOUS THERAPY}

With the "aging" of the immune system, the elderly may become less responsive to foreign antigens, which leads to a reduced resistance to pathogenic microorganisms and increased risk of nosocomial infection. Moreover, infection can manifest unusual manner. The rate of cell renewal decreases, increasing the period of recovery of health, fever may be absent or late a few days after the onset of infection, this can also lead to delusions, disorientation, among other acute changes in mental status, and also lethargy, decreased appetite and ability to perform ADLS. It is recommended that nursing orient the elderly, families and caregivers about the signs and symptoms of infection and care needed to prevent this complication ${ }^{2}$.

The elderly may be at increased risk for phlebitis, infiltration and extravasation due to changes in the integumentary system, fluid and electrolyte balance, nutritional deficiencies, and other disease processes pre-existing. Generally is subject to the prescription of parenteral therapies irritant and vesicant. However, these complications can also occur by improper selection of devices and the puncture site, loitering catheters and inspection and improper technique. The reduction in the response to noxious stimuli may lead to a delay in the verbalization of complaints, which may aggravate the situation and injuries. The patient should be instructed as to the recognition of the signs and symptoms of these complications ${ }^{2}$.

Already allergy risk is also increased due to exposure to multiple drug treatments or interventions. The higher the number/types of drugs, the greater the risk of this complication, occurrence of adverse effects and drug interactions. It is important when assessing the elderly; get the complete history of the use of medicines, including those without a prescription, herbal or homemade preparations, and any information from past experiences with reactions or sensitivities ${ }^{2}$.

\section{DISCUSSION}

The increasing elderly population in recent decades can be observed both in developed and developing countries. In Brazil, the number of elderly increased $600 \%$ from 
1960 to 2006 and, according to new estimates, the elderly population will triple in the next four decades, from 20 million in 2010 to approximately 65 million in $2050{ }^{10}$.

The aging population creates greater demand for private health care system, public or philanthropic due to increased comorbid chronic degenerative and susceptibility to infection and the occurrence of falls, depression, decreased hearing, vision and cognitive functional disorders ${ }^{10-11}$. The increase in this demand requires qualified professionals to improve the quality of care in intravenous therapy.

Care for the elderly requires special training and skills of nursing due to the complexity of the changes that occur with aging, longer hospital stays compared with other adults, high risk of functional ability during hospitalization and incidents that affect their safety ${ }^{8}$.

In the U.S., only $1 \%$ of nurses with higher education are certified in gerontology and only $3 \%$ have some training in this area ${ }^{12}$. In Brazil, there is no statistical data indicating the proportion, but imagine if devaluation even larger area. The professional trained in elderly care in intravenous therapy that is able to differentiate the processes of senescence and senility, and assess the patient, their family/carers to plan care in a safe and quality ${ }^{2,8}$.

When nurses have knowledge and skills to assess the elderly individually, collaboratively and in accordance with their age, it enables one infusional effective, and provides safety, comfort and quality in patient care. The family or caregiver is the main link of communication and support for the evaluation and planning of patient care ${ }^{2,4,12}$.

Education of patients, families and caregivers is essential in reducing errors and complications caused by health professionals because it allows their engagement in quality and safety programs. The patient should be encouraged to ask the professional if he washed his hands, to distinguish the schedules and prescription drugs and undergoing care and know the potential complications related to intravenous therapy ${ }^{7,13}$.

Regarding the choice of the site of puncture of peripheral catheter, one study ${ }^{14}$ with 933 adults and elderly patients in medical-surgical wards of a university hospital and two general hospitals Swedes showed that $45 \%$ of the records of the puncture site are made in peripheral member dominant upper and $35 \%$ in the hands and wrists. Despite the lack of studies that analyze the quality of care records, regions punched and peripheral catheterrelated complications, this device is the most used in hospitals. Furthermore, the lack of knowledge and nursing protocols regarding the particularities of venous access in the elderly can greatly increase morbidity, hospitalization and hospital costs ${ }^{14-15}$.

Italiano16 observational study, conducted in areas of hospital clinical and surgical hospital with 427 patients between 12 and 101 years old, has shown a significant increase of thrombophlebitis in the elderly, and the risk of this complication is directly linked to aging, ie, adults aged 18 and 30 years had very low prevalence in those with 30-60 years there was an increase in the prevalence and in patients aged greater than or equal to 61 years, this increase was even greater. Furthermore, this complication related to the puncture sites, concluding that the risk of thrombophlebitis are higher when catheters are placed in the dorsal region of the hand, compared to punctures in the forearm.

The preservation of the venous network is a priority in therapy and intravenous catheters placed in the hands and joints cannot be reliably determined in elderly patients with fragile veins and tissue, leading to loss of venous access, seepage, leakage, 
interruption and delay in infusion prescribed impossibility puncture of a future in the same region due to irreversible damage to the vascular structure and losses in ADL because the patient pain and functional and tissue damage in the affected limb $b^{15,17}$.

As for the choice of the diameter of the catheter, the documents with specific recommendations for the elderly ${ }^{(2,4-5)}$, indicating that they are smaller than those given to adults. The use of smaller gauges is recommended, because larger tubes can damage blood perfusion and increase the pressure in the vessel, resulting in leakage, extravasation, phlebitis, thrombus formation and hematoma ${ }^{15}$.

The selection of a suitable antiseptic to the elderly is quite complex when considering the technical, cost, accessibility of the product and even the different manufacturer's instructions and existing studies ${ }^{2,4-6}$ international guidelines recommend the use of alcoholic chlorhexidine 0,5\% higher than for skin antisepsis clean for adult and pediatric patients. This solution, despite higher costs, it is less allergenic than iodophors and also has residual action and found to be more effective than other antimicrobial solutions. However, it is the basis of alcohol can dry the skin.

An alternative to replacing the alcoholic solution is to use an aqueous solution of $2 \%$ chlorhexidine, but this does not dry naturally, requiring the aid of a sterile gauze after application of the product ${ }^{18}$. However, a case study carried out in London with extremely low birth weight neonates reported episodes of burns caused by use of this antiseptic ${ }^{19}$, it was due to skin fragility of the newborn. The CDC states that there is no sufficient scientific evidence to indicate the aqueous chlorhexidine for skin antisepsis ${ }^{6}$.

Regarding the technique of puncture veins/fragile tissues, the tourniquet should be avoided whenever possible. Alternative technologies which use infrared light (fleboscopic) can aid in visualization during catheter insertion. Furthermore, when puncturing the vein, you must use the bevel facing up, small angles (15-30 degrees), insert the needle firmly but slowly to realize the return blood and avoid breaking the opposite wall ${ }^{15}$. It is also necessary to ensure the stabilization of vein/skin to reduce pain and facilitate the procedure.

On the setting and achievement of the insertion site dressings, one should consider that the elderly are subject to accidental manipulation of the dressing and catheter due to sensory and cognitive changes, leading to loss of integrity of the skin or devices and risk for contamination and infection. The skin care of the elderly is extremely important, because cell renewal is diminished and the skin becomes more fragile and their healing slower ${ }^{2}$.

When fixing the catheter it must take special care of plastics or fabric, which have more potent activity than the adhesive paper. It is recommended to use the minimum possible this material and after the procedure cover the catheter dressing transparent. The tracks tubular or glove should be used for reducing the amount of adhesives for attachment $^{15}$, but there is the possibility of choosing catheters that have safety devices such as sutures or cuff, but they must be evaluated benefits and risks of inflammatory or infectious. The Guidelines state that international ${ }^{2,4-6}$ using fasteners catheters without sutures increases the residence time of the device, reduces infection rates and other complications.

To remove these stickers is important to follow the manufacturer's guidelines to avoid skin damage. It is recommended in some cases, the use of removers, skin traction to 
reduce adhesion and slowly remove the dressing. If the region is damaged even with these precautions, should be treated like any other wound and analyze the need for catheter removal until healing of the site ${ }^{15}$.

The wound dressing should consider minimal handling of the infusion system as a way to reduce infection and loss or damage of devices. The principal means of contamination/infection and catheter displacement is through the hands of professionals when handling catheters, dressings and devices accessories infusion ${ }^{4-6}$.

Although hand washing and skin preparation are two strategies emphasized by $\mathrm{CDC}^{8}$ in control and prevention of catheter-related infection, in the case of the elderly, prevention of skin lesions have similar degree of importance.

Some Guidelines analyzed ${ }^{3-5}$ indicate the replacement of transparent dressings in adults every 5-7 days for central venous catheters or when damp or soiled ungluing and pediatric/neonatal possessing the fragile skin should be changed, both in central venous catheters and in peripheral when assessing necessary. As for dressing change of peripheral catheters in adults, it is recommended the replacement of such a dressing only when this is not healthy.

Since the $\mathrm{CDC}^{6}$ Guideline recommends transparent dressing change every 7 days in adult or when it is not intact, and only when evaluating pediatric patients is necessary because of the risk of displacement. However, there is sufficient scientific evidence to support recommendations specific to the elderly population, but taking into consideration the fragility of their skin and tissue, the risk of displacement, infiltration and extravasation injury when handling the dressing, it is suggested that this should be maintained as its integrity is preserved.

It also indicates the placement of a flag on the headboard, or a visible, indicating the weakness of the vein and the patient's skin ${ }^{15}$. In Brazilian studies with hospitalized elderly, nursing diagnosis is most identified related to impaired skin integrity ${ }^{20-21}$. Already one U.S. study with elderly receiving home intravenous therapy in identified that complications related to catheters, the most commonly reported were the displacement and occlusion catheters and rarest blood infection.

With regard to accidents/falls, Brazilian literature does not have enough data on the incidence of these events and their causes intrinsic and extrinsic in the hospital environment, especially regarding the standardization of equipment and maintenance therapy (intravenous catheters, IV pole, walkers). However, the nursing diagnosis "risk to drop " features prominently in the investigations made in hospitals ${ }^{20-21}$.

The infusion monitoring is important because changes in cardiac and renal function are common in aging and disease conditions. Thus, these patients require careful monitoring and preparation of parenteral fluid infused. The education and use of security mechanisms are needed to prevent the patient manipulate inadvertently mechanisms for flow control may occur free or bolus infusion. Sound and light indicators help patients with sensory deficits hearing and vision) ${ }^{2,23}$.

The management of complications involves standardization processes of institutional policies and procedures to ensure the safety of the elderly patient. A complication is defined as an unexpected or unwanted results associated with the proposed therapy, usually associated with risk factors such as the nature of the drug, duration of therapy, individual 
characteristics of the patient, the professional technical ability, location and type of intravascular devices ${ }^{3}$.

The complications related to intravenous therapy is considered an important quality indicator for hospital and care provided by the nursing staff. Its incidence can greatly enhance institutional spending, length of stay and severity of the patient's condition. Thus, notification is essential and ongoing education of nursing the most effective measure to reduce $\mathrm{it}^{2-6,8}$.

The elderly are especially vulnerable to these events, because many times, the nursing staff is not trained for specialized care and there is an exclusive area for the care of this population in health institutions ${ }^{2,8}$. In addition, studies show that the elderly most common adverse events committed by nursing are related to intravenous therapy ${ }^{7-8,23-26}$.

In a study conducted with elderly brasileiro8 hospitalized in emergency wards and surgical clinic of a university hospital in the state of São Paulo, which examined the medical records, the most frequent complications were: infiltration, obstruction or phlebitis in peripheral venous access before $72 \mathrm{~h}$ punch, followed by pressure ulcer, fall, loss of nasogastric tube, signs of inflammation on central venous access, containment injury , bruises technical incorrect administration of enoxaparin sodium, administration of medication by incorrect insertion and hyperemia in drain vacuum. In the records that have been no reports of adverse events, the elderly had longer hospital stays.

Another study on adverse events, with a sample of $78 \%$ of the elderly (over 60 years) and $22 \%$ of adults (over 18 years) admitted to a private hospital in São Paulo, there was very significant percentage of related events to medication errors (prevalence of $45-88 \%$ ) and central venous catheters (prevalence 10-57\%) ${ }^{24}$.

In relation to catheter-related bloodstream infections, there is insufficient data to compare rates among adults and elderly or demonstrating the susceptibility of the elderly to this complication ${ }^{11,27}$. A Brazilian multicenter study that examined risk factors for bloodstream infections related to catheters in six intensive care units, with 555 adult patients (18 years), using CVC (total of 928 catheters), concluded that the age is not associated with increased bloodstream infections ${ }^{27}$.

The prevention and control of infection in the elderly following the same criteria as the other populations, such as using proper aseptic techniques, maximal barrier protection sterile, proper hand washing, education and training of professionals, patients, caregivers and family members and other strategies applied simultaneously and according to institutional protocols ${ }^{4-6}$.

\section{CONCLUSION}

The provider is responsible for safe care for elderly patients and meet their particular demonstrates respect and ethics for this population. Moreover, health care institutions should have policies for quality and standardization of procedures specific to 
the elderly undergoing intravenous therapy and encourage the registration of complications to subsidize improvements and effectively meet the needs of these individuals.

There is little national and international literature on the special care of the elderly in intravenous therapy and this directly affects the quality and safety of nursing care to this population, since the specific guidelines are not supported by experimental studies, clinical or epidemiological studies. The development of protocols for the practice of the elder care also becomes inconsistent when there are no records of specific complications, unanticipated events and evolution of care for these individuals.

Despite increasing elderly population and the large number of hospitalizations in this population, many schools and nursing professionals are not prepared for the recognition of factors involving the processes of senescence and senility and implementation of safe practice for the elderly. In contrast, bibliographies and recommendations described in this study show how the elderly are different from a young adult and this leads to numerous changes and adaptations in the planning and development of nursing care, including demonstrates the need for a sector hospital with gerontological a multidisciplinary team specialize.

The specific content for the elderly in the analyzed documents can be adapted to national realities, but clinical studies are needed to confirm its efficacy and applicability, ensuring the quality and safety of care for elderly patients in intravenous therapy.

\section{REFERENCES}

1. Camp-Sorrell, D. State of the science of oncology vascular access devices. Seminars in Oncology Nursing. May, 2010;26(2):80-87.

2. Infusion Nurses Society. Policies and procedures for infusion nursing of the older adult. INS; 2004.111 p.

3. Infusion Nurses Society Brasil. Diretrizes práticas para terapia intravenosa. 2008. $53 p$.

4. Infusion Nurses Society. Infusion Nursing Standards of practice. Journal of Infusion Nursing. Jan/Feb, 2011; 34 Suppl 1: S1-110.

5. Infusion Nurses Society. Policies and Procedures for Infusion Nursing.4nd edition: INS; 2011. 162p.

6. O'Grady NP, Alexander M, Burns AL, Dellinger P, Garland J, Heard SO, et al. Guidelines for the prevention of intravenous catheter-related infections - 2011. Center for Disease Control. Departament of Health \& Human Services. USA. 2011; 83p.

7. Lavery I. Intravenous practice: improving patient safety. British Journal of Nursing. 2011; 20(19):S1-S6.

8. Santos JCD, Ceolim MF. Nursing iatrogenic events in hospitalized elderly patients. Rev. Esc. Enferm: USP; 2009. 43(4):810-817. 
9. Sá-Silva JR, Almeida CD, Guindani JF. Pesquisa documental: pistas teóricas e metodológicas. Rev Bras de História \& Ciências Sociais. Jul, 2009; 1(1):1-15.

10. Gragnolati $\mathrm{M}$, Jorgensen $\mathrm{OH}$, Rocha R, Fruttero A. Envelhecendo em um Brasil mais velho. Banco Internacional para a Reconstrução e o Desenvolvimento. Banco Mundial, Washington (D.C). 2011; p. 1-62.

11. Oliveira VCR, Nogueira LS, Andolhe, RA, et al. Evolução clínica de adultos, idosos e muito idosos internados em Unidade de Terapia Intensiva. Rev. Latino-Am. Enfermagem. Nov/Dez 2011; 19(6):[08 telas].

12. Thornlow DK, Auerhahn C, Stanley J. A necessity, not a luxury: Nurses to care for older adults. Journal of Professional Nursing. Mar-Apr, 2006. 22(2):116-122.

13. Woodward HI, Mytton OT, Lemer C, et al. What have we learned about intervantions to reduce errors? Annu. Rev. Public Health. 2010; 31:379-397.

14. Ahlqvist $M$, Berlund $B$, Wirén M, Klang B, Johansson E. Accuracy in documentation - a study of peripheral venous catheters. Journal of Clinical Nursing. Clinical Issues. 2009; 18:1945-1952.

15. Miller SL. Vascular access challenges: small, fragile veins and tissue-paper skin. I.V. Rounds. Nursing2012 [Internet]. Feb 2012. [acesso em: 03 mar 2012];62-63. Disponível em: http: / / www.nursingcenter.com/lnc/journalarticle?Article_ID=1292787.

16. Cicoline G, Bonghi AP, Labio LD, Mascio RD. Position of peripheral venous cannulae and the incidence of thrombophlebitis: an observational study. Journal of advanced nursing. 2009; 65(6):1268-1273.

17. Schulmeister L. Vesicant chemotherapy extravasation management. British Journal of Nursing. 2011; 20(19), 2011.

18. Sharpe E. Tiny patients, tiny dressings: A guide to neonatal PICC dressing change. Advances in Neonatal Care. 2008; 8(3):150-162.

19. Lashkari HP, Chow P, Godambe S. Aqueous $2 \%$ chlorhexidine-induced chemical burns in an extremely premature infant. Arch Dis Child Fetal Neonates. 2012; 97(1).

20. Guedes HM, Nakatani AYK, Santana RF, Bachion MM. Identificação de diagnósticos de enfermagem do domínio segurança/proteção em idosos admitidos no sistema hospitalar. Rev. Eletr. Enf. [Internet]. 2009 [acesso em 03 mar 2012]; 11(2):249-56. Disponível em: http://www.facenf.uerj.br/v18n4/v18n4a02.pdf.

21. Bitencourt GR, Santana RF, Cavalcanti AC, Cassiano KM. Comparação de diagnósticos de enfermagem em adultos e idosos hospitalizados no pós-operatório. Rev. Eletr. Enf. [Internet]. Out/dez, 2011 [acesso em 03 mar 2012];13(4):604-11. Disponível em: http://www.revistas.ufg.br/index.php/fen/article/view/15172.

22. Cox AM, Malani PN, Wiseman SW, Kauffman CA. Home intravenous antimicrobial infusion therapy: a viable option in older adults. J Am Geriatr Soc. 2007; 55:645-650.

23. Gorski LA. Speaking of Standards...Standard 3: Older Adult Patients. Journal of Infusion Nursing. Jul/aug 2008; 31(4): 211-2.

24. Nascimento CCP, Toffoletto MC, Gonçalves LA, Freitas WG, Padilha KG. Indicators of healthcare results: analysis of adverse events during hospital stay. Rev Latino-am enfermagem. Jul/Ago, 2008. 16(4):746-51.

25. Peate I. Keeping patients safe: protecting this priority. British Journal of Nursing. 2011; 20 (17): 11-9. 
26. National Patient Safety Agency. NRLS Quartely Data. 2011 [acesso em 15 ,ar 2011]. Disponível em http://tinyurl.com/5uwjtlj.

27. Bicudo D, Batista R, Furtado GH, Sola A, Alexandrino E, Medeiros S. Risk factors for catheter-related bloodstream infection: a prospective multicenter study in Brazilian intensive care units. Braz J Infect Dis. 2011; 15(4):328-331, 2011.

Received on: 09/09/2012

Required for review:23/05/2013

Approved on: 03/10/2013

Published on: 01/01/2014
Contact of the corresponding author: Rosemeiry Capriata de Souza Azevedo Rua C, $n^{\circ} 33$, apto 501. Cond. Matisse Residences, Miguel Sutil, Cuiabá, MT, Brasil, 78048-298. Email:capriata@terra.com.br 